\title{
Principles of Internal Fixation in Maxillofacial Surgery
}

\author{
Abhilasha Yadav
}

\subsection{Introduction}

Road traffic accidents (RTA) are one of the primary etiologies of craniomaxillofacial fractures. Open reduction and internal fixation (ORIF) is the most important treatment modality to restore the compromised form and function. Adequate reduction and fixation with miniplate osteosynthesis is the essential component of management.

\subsubsection{Association of Osteosynthesis (AO Principles)}

The following are guidelines for internal fixation based on the four basic principles formulated by AO in 1958 .

(A) Anatomic reduction: Fracture reduction and fixation to restore normal anatomy

(B) Stable fixation: Fracture fixation with relative or absolute stability, as required by the patients injury and type of fracture

(C) Preservation of blood supply: By gentle reduction and careful handling along with preservation of vascularity of soft tissues and the bone

(D) Early and active mobilization: Rehabilitation of the injured part and the patient as a whole with early and safe mobilization
A. Yadav $(\square)$

Department of Oral \& Maxillofacial Surgery, Awadh Dental

College \& Hospital, Jamshedpur, Jharkhand, India

\subsection{History}

1. Plating of fractures can be traced back to 1895 when a metal plate was first introduced by Lane for internal fixation. It was abandoned due to its drawback of corrosion [1].

2. Subsequently Lambotte in 1909 and Sheman in 1912 introduced plates for fixation, but due to insufficient strength, their designs were abandoned [1].

3. Eggers in 1948 developed a plate which was structurally weak resulting in instability of fixation [1].

4. In maxillofacial surgery, the interest in rigid fixation began with the treatment of fractures of edentulous mandible, as the fractures located in edentulous mandibular segments were easier to manage.

5. Keys to fast and economic bone healing are optimal reduction of fracture ends and maximum stabilization of fracture area. Simplest way to achieve these goals is to apply the principles of axial compression of fracture ends. This principle was first advocated by Belgian Surgeon Davis in 1994 and later adopted by ASIF (association for the study of internal fixation).

According to him, there was a need for compression between the fragments of fractures. He used a plate called coaptens to achieve this goal, which increased stability and suppressed interfragmentary motion. The mode of healing initiated by this is called soudure autogene (autogenous welding) now known as primary bone healing.

6. In 1967, mandibular compression screw (MCS) was used in oral and maxillofacial surgery (OMFS) in edentulous fractured mandible while performing first compression osteosynthesis. Self-tightening/automatic MCS plate was developed by Luhr in 1968. Later, dynamic plates were advocated for surgery of long bones with subsequent application in mandibular fractures. 
Table 51.1 History of development of fracture management modalities

\begin{tabular}{|c|c|c|}
\hline 1881 & Glimer & $\begin{array}{l}\text { On either sides of the fracture, two heavy } \\
\text { rods }\end{array}$ \\
\hline 1886 & Hansmann & Retrievable bone plates \\
\hline 1945 & Christiansen & In mandibular fracture-tantalum plates \\
\hline 1956 & Bagby & First compression plate \\
\hline 1960 & $\begin{array}{l}\text { Luhr and } \\
\text { Mittlmeir }\end{array}$ & Improved mandibular compression plates \\
\hline 1969 & $\mathrm{AO} / \mathrm{ASIF}$ & Dynamic compression plates (DCP) \\
\hline $1970 \mathrm{~s}$ & $\begin{array}{l}\text { Brons and } \\
\text { Boeriing }\end{array}$ & Lag screws \\
\hline 1973 & $\begin{array}{l}\text { Schmoker and } \\
\text { Spiessel }\end{array}$ & $\begin{array}{l}\text { (EDCP) eccentric dynamic compression } \\
\text { plates }\end{array}$ \\
\hline 1973 & Michelete & Miniplates \\
\hline 1975 & Champy & Monocortical screws principal for fixation \\
\hline 1977 & Luhr & $\begin{array}{l}\text { Compression plates for the first time in } \\
\text { management of fracture mandible }\end{array}$ \\
\hline 1977 & Spiessel & $\begin{array}{l}\text { For mandible fracture advocated AO/ASIF } \\
\text { principle }\end{array}$ \\
\hline 1989 & Bos & Resorbable plates and screws \\
\hline 1994 & & $\begin{array}{l}\text { Dynamic compression plate with locking } \\
\text { compression plate }\end{array}$ \\
\hline 2011 & & $\begin{array}{l}\text { Development of locking compression } \\
\text { plate with combination holes }\end{array}$ \\
\hline
\end{tabular}

\subsubsection{Evolution of Fixation Methods}

History of development of fracture management modalities [2-4] (Table 51.1)

\subsection{Concept of Bone Healing}

\subsubsection{Secondary Bone Healing (Fig. 51.1)}

\subsubsection{Stage I: Inflammation Induction}

Immediately after fracture, hematoma formation occurs; hematoma plays a vital role in the angiogenesis of the healing fracture. Subsequently, inflammatory cells, stem cells, and fibroblasts initiate inflammatory response and enhance angiogenesis. Cytokines which helps in bone repair are released in this phase and hematoma is removed. Within 3 days, thin layer of fibrous tissue covers the periosteal surface of fractured bone. The cortical bone adjacent to fracture site becomes necrotic which later gets remolded by multinucleated osteoclast.

\subsubsection{Stage II: Fibrocartilaginous (Soft) Callus Formation}

Dense fibrous tissue, cartilage, and fibrocartilage formation occurs due to organization of subperiosteal hematoma; soft callus is composed of internal (endosteum of marrow cavity and lining of Haversian canal) and external components (periosteum and organizing hematoma) and continued proliferation of osteoblasts; fibrocartilaginous tissue begin to calcify as the periosteal and endosteal circulation develops. The conversion of chondrocytes to osteocytes occur and the entire callus is converted to immature woven bone.

\subsubsection{Stage III: Hard Callus Formation}

After 3-4 weeks of fracture, the hard callus begins to form and osseous union of the fractured cortical bone starts.

\subsubsection{Stage IV: Remodeling}

The trabeculae orient themselves in the direction of functional pressures after bone formation.

\subsubsection{Primary Bone Healing (Contact and Gap Healing)}

Healing without callus formation is called as primary bone healing. When there is direct apposition of cortical bone surfaces, contact healing occurs. Osteoclasts widen the Haversian canals on either side of the fracture and move toward each other. The cortical bridging occurs in 8 weeks and is usually completed in 16 weeks. In gap healing also primary bone healing occurs; gap as wide as $100 \mu \mathrm{m}$ can be filled with mature lamellar bone (Fig 51.2).

\subsection{Biomechanics of Facial Skeleton [5]}

\subsubsection{Mandible Fractures}

The mandible is a class III lever with:

- Condyle as fulcrum.

- Bite load as a resistance force.

- Masticatory muscles as applied force.

Simple beam mechanics described the traditional biomechanical properties of mandible, which represents compression at inferior border and tensile forces on the superior border with an applied anterior load (Fig. 51.3). The "neutral axis" is the line of zero stress where the tensile forces become compressive, and it is approximately at the level of the inferior alveolar canal. Compression and tension will be produced in symphysis region due to torsional forces.

The muscles inserting on the mandible and forces exerted by these muscles during function, determine the tension and compression zone in cases of fracture mandible.

The direction of the muscular forces acting on the mandible by temporalis, lateral pterygoid, pterygomasseteric sling, and suprahyoid musculature is shown by arrows in Fig. 51.4. For successful treatment of facial fractures in the form of rigid fixation, the understanding of biomechanics of facial injury is very important. 
Fig. 51.1 Fracture healing

1. Hematoma formation

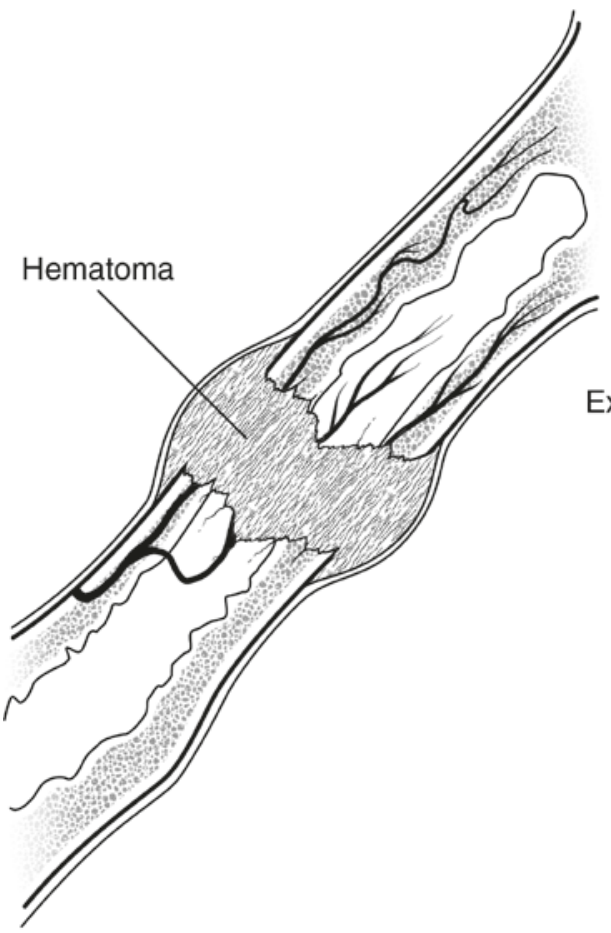

3. Bony callus formation

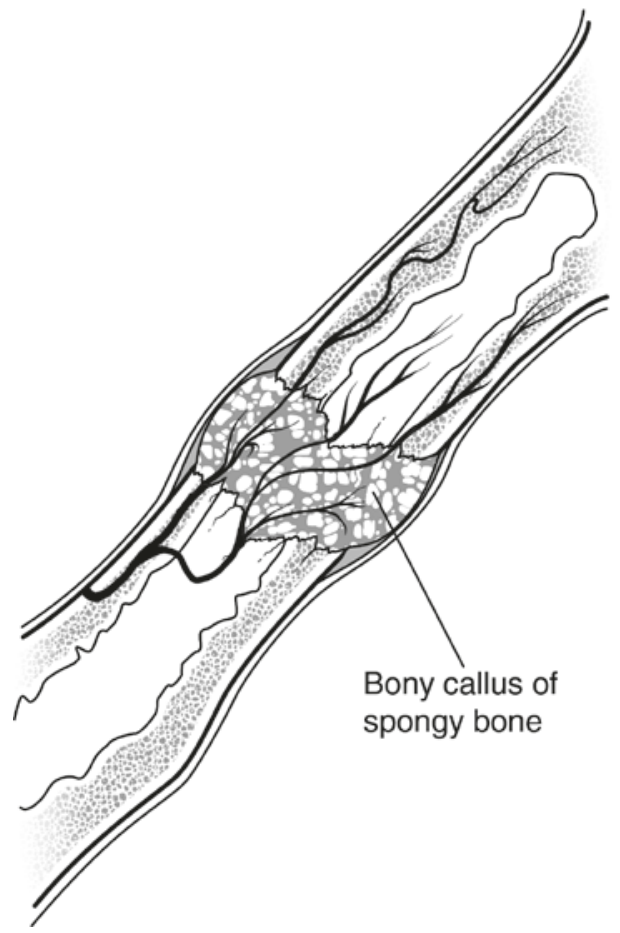

2. Fibrocartilage callus formation

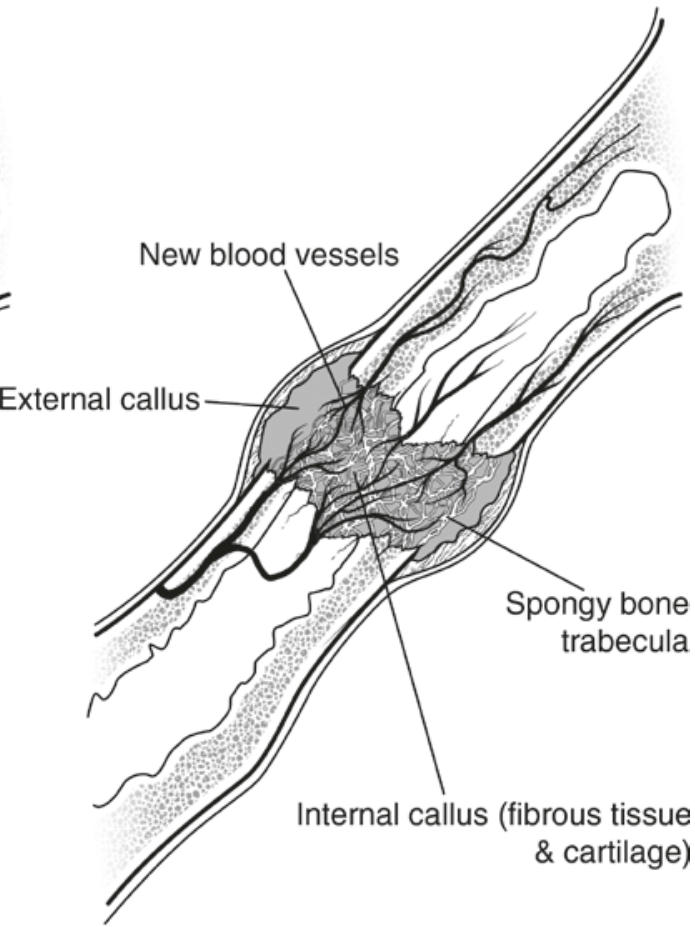

4. Bone remodeling

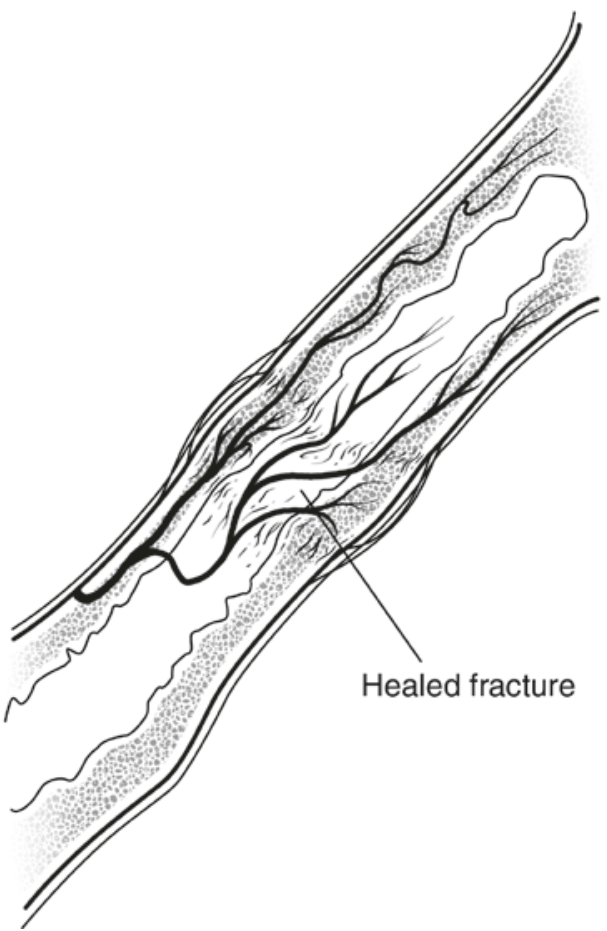

CAssociation of Oral and Maxillofacial Surgeons of India 


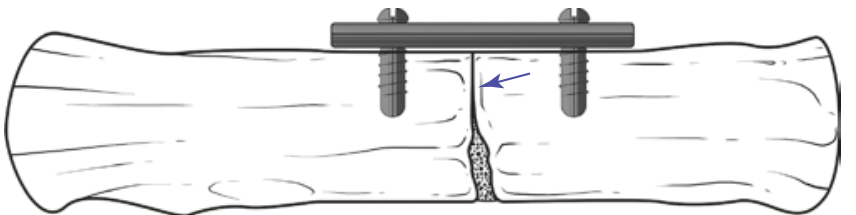

(CAssociation of Oral and Maxillofacial Surgeons of India

Fig. 51.2 Contact and gap healing (arrow denotes contact healing)

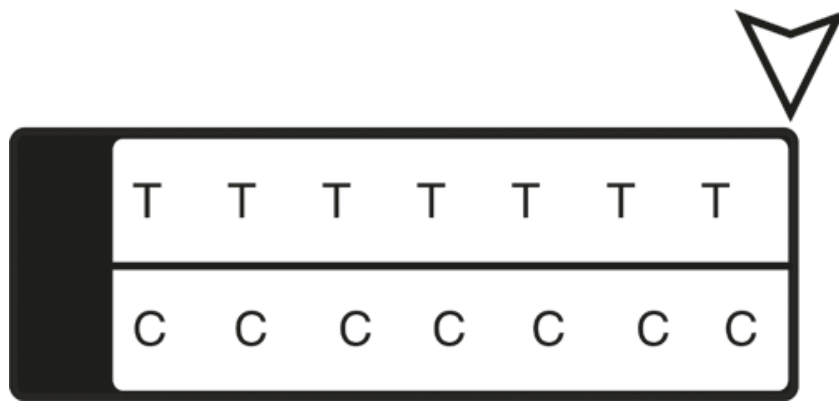

(C)Association of Oral and Maxillofacial Surgeons of India

Fig. 51.3 Tensile and compressive force mechanism

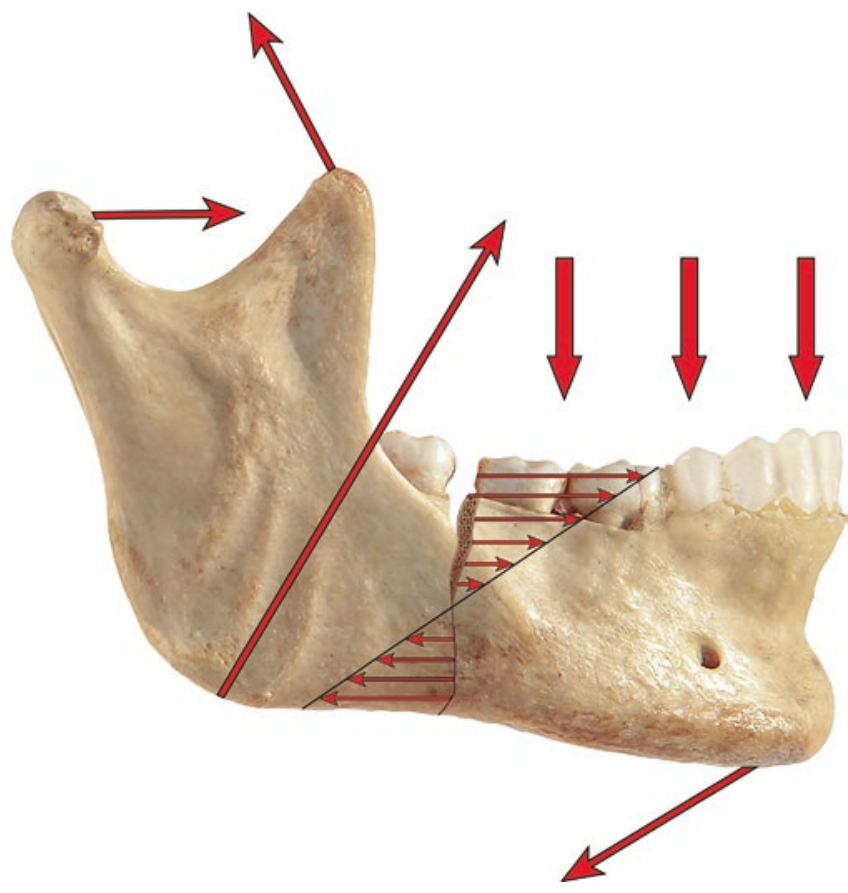

CAssociation of Oral and Maxillofacial Surgeons of India

Fig. 51.4 Direction of muscular forces

\subsubsection{Midface Fractures}

Midface generally does not show muscle forces acting on them except for zygomatic bone, on which masseter exerts the primary force which can create notable bony displacement causing inferior and medial displacement especially in the presence of temporalis fascia disruption (Table 51.2).
Table 51.2 The four articulations of zygoma with their functions in management of fracture

Frontozygomatic suture Received greatest tensile forces and is the important site for fixation

\begin{tabular}{l|l} 
Infraorbital rim & Thin bone, least important site for
\end{tabular}
Zygomaticomaxillary buttress

Zygomaticotemporal suture fixation

Best site for fixation to counter the force of masseter muscle

Least important site for plating

\subsection{Functions of Plates}

\subsubsection{Compression}

Compressing together the main fragments of a single plane fracture can result in absolute stability, i.e., the complete abolition of interfragmentary movement. Interfragmentary compression in single plane, as in diaphyseal fractures, can be achieved by exploiting the eccentric loading capabilities of the dynamic compression family of plates.

The screw is inserted in a neutral mode, and plate was fixed to the right-hand fragment. In an eccentric (load) mode, a screw is then inserted into the left-hand fragment. As the load screw is fully inserted, it engages and slides down the sloping surface of the plate hole, and the screw and bone move toward the fracture, compressing it.

If the plate that exerts axial compression is exactly contoured to the anatomically reduced fracture surface, there will be some gapping of the opposite cortex when the plate is tensioned by tightening the load screw. This is due to the compression being maximal immediately beneath the plate and not evenly distributed over the whole area of the fracture plane. The solution to this problem is to "overbend" the plate so that its center stands off 1-2 $\mathrm{mm}$ from the anatomically reduced fracture surface. Slight gaping of the cortex will occur directly underneath the plate when the neutral side plate is applied to the bone. The tightening of load screw causes tension in the plate and compresses the fracture evenly across the full diameter of the bone.

\subsubsection{Neutralization}

A primary lag screw fixation, exerting interfragmentary compression, can be vulnerable to disruption by physiological bending and/or rotational forces. Such a primary fixation is usually protected by the use of a plate, spanning from one main fragment to the other-this "neutralizes" the disruptive forces. All such forces are then transmitted via the plate and bypass the primary lag screw fixation. 


\subsubsection{Tension Band}

If a body with a fracture is loaded at each end, over a bending point (fulcrum), tension (distraction) forces are generated, maximal on the side opposite the fulcrum, and angulation occurs. However, if an inelastic band, such as a plate, is anchored to the tension side of the body, same load will generate compression across the fracture interface. This is known as the tension band principle.

\subsection{Fixation Methods and Devices [6]} (Table 51.3)

Commonly used devices used for fixation are wires, staples, pins, and screws [6].

\subsubsection{Material}

Most commonly used materials are titanium (Ti-6Al-4V) and stainless steel (316L). Stainless steel has been used because of its greater biocompatibility and corrosion resistance. Since 1980 titanium was used in maxillofacial surgery.

\subsubsection{Rigid Fixation}

The internal fixation is defined as the placement of wires, plates, screws, rods, pins, and other hardware to stabilize the fracture fragments.

\subsubsection{Rigid Internal Fixation (RIF)}

RIF is defined as "bone fixation of any form in which biomechanical forces are either countered or used to stabilize the fragments of fracture and permits loading of bone to permit active action" [7].

\subsubsection{Examples of RIF}

Examples of RIF are the use of bone plates and screws, two lag screws, and use of reconstruction plate with three screws on each side of the fracture fragment. Use of long compression plate is also included in the rigid internal fixation examples.

Table 51.3 Fixation methods and devices

\begin{tabular}{|c|c|c|c|}
\hline \multicolumn{4}{|c|}{ Fixation methods } \\
\hline Wires & Staples & Pin & Screws \\
\hline & $\begin{array}{l}\text { Pneumatically driven } \\
\text { staples }\end{array}$ & \multirow[t]{2}{*}{$\begin{array}{l}\text { Kirschner } \\
\text { wires }\end{array}$} & $\begin{array}{l}\text { Cancellous } \\
\text { screw }\end{array}$ \\
\hline & Prebent staple legs & & Cortical screw \\
\hline
\end{tabular}

Healing: In the rigid internal fixation, no callus formation is formed during bone healing. The fracture bones heal by a process of Haversian remodeling. This primary or direct bone union requires immaculate immobilization between osseous fragments, i.e., minimum gap between the rigid fixation. Examples of rigid fixation for fracture mandible are shown in Fig. 51.5a,b.

\subsubsection{Nonrigid Internal Fixation}

It is a kind of fixation that is not strong enough to prevent interfragmentary motion completely. Thus interfragmentary motion is the differentiating factor between rigid and nonrigid fixation. Any mobility between fragments stabilized through internal fixation on active usage of skeletal structure signifies nonrigid fixation.

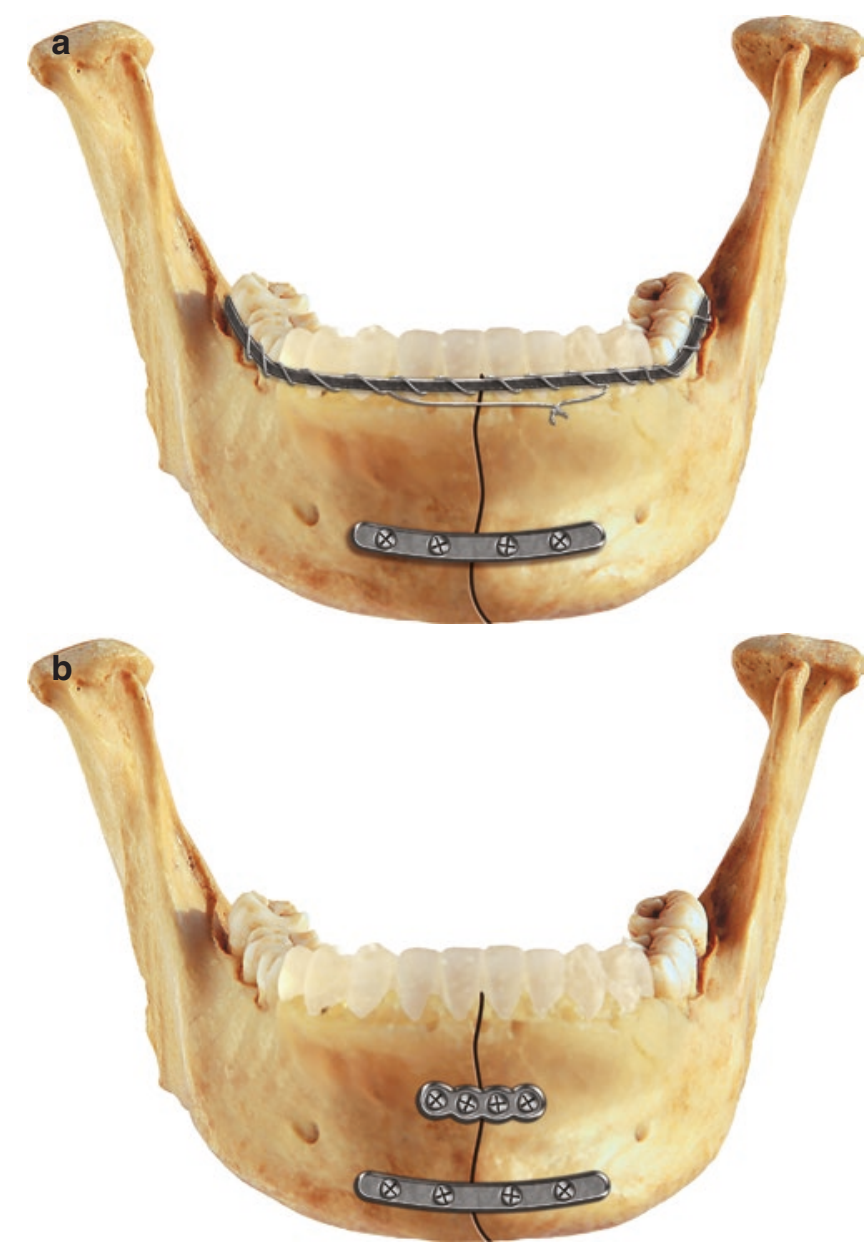

CAssociation of Oral and Maxillofacial Surgeons of India

Fig. 51.5 (a, b) Techniques of rigid fixation for mandibular fracture. (a) Fixation with single miniplate and tension band; (b) fixation with two miniplates 
Transosseous wiring across a fractured mandible is a good example of nonrigid fixation. The wire is unable to neutralize torsion/or shear forces and requires other fixation methods like MMF (maxillomandibular fixation).

Healing: The bone healing that occurs under the condition of mild mobility between fragments is called as secondary bone healing. There is deposition of periosteal callus in such circumstances, followed by resorption of fragment peripheries and tissue differentiation through various stages from fibrous to osseous healing.

\subsubsection{Semirigid Fixation}

Semirigid fixation is based on load-sharing osteosynthesis. Semirigid fixations include the use of:

- Lag screw

- Miniplates and microplate

- Locking plates

- Resorbable plates

- Three-dimensional plates

\subsubsection{Load-Bearing Versus Load-Sharing Fixation (Table 51.4)}

Table 51.4 Load-bearing versus load-sharing fixation

\begin{tabular}{|c|c|c|}
\hline & Load-sharing fixation & Load-bearing fixation \\
\hline $\begin{array}{l}\text { Definition/ } \\
\text { explanation }\end{array}$ & $\begin{array}{l}\text { Internal fixation of } \\
\text { inadequate stability to } \\
\text { withstand the } \\
\text { functional loads across } \\
\text { the fracture }\end{array}$ & $\begin{array}{l}\text { Fixation that is capable of } \\
\text { withstand the entire load } \\
\text { applied during the } \\
\text { functional activities to the } \\
\text { mandible }\end{array}$ \\
\hline Indication & $\begin{array}{l}\text { 1. Simple linear } \\
\text { fractures } \\
\text { 2. Mandibular } \\
\text { fractures }\end{array}$ & $\begin{array}{l}\text { 1. Mandibular comminuted } \\
\text { fractures } \\
2 \text {. Loss of segment of } \\
\text { mandible due to injury } \\
3 \text {. Fracture with very less } \\
\text { boney interface because of } \\
\text { atrophy }\end{array}$ \\
\hline Material used & $\begin{array}{l}\text { Stainless steel, } \\
\text { titanium } \\
2.0 \mathrm{~mm} \text { miniplating } \\
\text { systems }\end{array}$ & $\begin{array}{l}\text { Stainless steel, titanium } \\
2.3 \mathrm{~mm}, 2.4 \mathrm{~mm}, 2.7 \mathrm{~mm} \\
\text { diameters, mandibular } \\
\text { reconstruction bone plate }\end{array}$ \\
\hline Complications & $\begin{array}{l}\text { Due to inadequate } \\
\text { bone stock adjacent to } \\
\text { comminuted fractures, } \\
\text { load-sharing plates } \\
\text { should be avoided }\end{array}$ & $\begin{array}{l}\text { Failure by either screw } \\
\text { loosening or plate fracture }\end{array}$ \\
\hline
\end{tabular}

\subsection{Classification of Plating System [8]}

(A) Luhr vitallium maxillofacial systems

(I) Mandibular compression screw system

(II) Mini system

(III) Micro system

(IV) Mandibular reconstruction system

(B) Champy's system

(C) AO/ASIF maxillofacial implant system

(I) DCP, EDCP

(II) Reconstruction plates

(D) The Würzburg titanium system for rigid fixation

\subsubsection{Locking Plate-Screw Systems}

In the late 1950s, AO group put forth the tenets which are followed in traditional plates and screws. This included exposure of fracture with anatomic reduction and internal fixation of fracture fragments with the desired result of anatomic bone union [9]. The stability of these plates is achieved by locking the plates by the screws.

Conventional screw - bone plates system requires plate to adapt precisely. In the absence of this contact, the tightening of screw will draw the segments of the bone toward the plate which results in change of the occlusion and bony segments.

On the other hand, the locking plate-screw system does not require the intimate contact of plate to the underlying bone in all the areas. The screw tightening locks the plate and thus stabilizes the bone segments without compressing the bone to the plate. Alteration in reduction is impossible after screw insertion.

According to Herford and Ellis [10], the locking plate and screw system are simple to use. Like compression plate it does not require plate to be compressed to the bone.

Klotch et al. [11] also concluded that the locking plates require less time due to less bending and faster application with good results.

Locking plate and screw come in two designs, i.e.:

- Threaded locking plate and screw (Conventional)

- Tapered locking screw and plate (New generation) 
The threaded locking plate - screw system features corresponding machined threads incorporated in both the screw and plate. Whereas, the tapered locking screw - plate system has a screw head which is tapered in shape with machined threads, with the plate either having no machined threads or a single machined thread incorporated into its design. This facilitates a more flexible locking mechanism which allows for screw angulation of upto 10 degrees, in comparison to the threaded locking system which needs absolute perpendicular screw placement [12].

\subsubsection{Reconstruction Plates}

The rigid plates with $2.7 \mathrm{~mm}$ bicortical screws were introduced by AO/ASIF in 1972 [13].

The main advantage attributed to the non-locking reconstruction plate, is its "load bearing" principle. Scolozzi and Richter [14], used the $2.4 \mathrm{~mm}$ AO Titanium plates for the management of mandible fractures, with good outcomes and very less complications.

They are available in different shapes for specific areas like angle reconstruction plate (Fig. 51.6), condylar reconstruction plate (Fig. 51.7), and straight reconstruction plate with different lengths.

\section{Indications}

1. Large defect of mandible after massive trauma

2. After mandible resection due to tumors or osteoradionecrosis

3. Commonly used in comminuted fractures of mandible, sometimes in combination with miniplates

4. To support the bone grafts in mandibular reconstruction

The advantages of rigid fixation with grafting include immediate jaw function and excellent stabilization of graft. The main disadvantage at the graft site is disuse osteoporosis or "stress shielding." This phenomenon occurs when rigid plates absorb the mandibles functional stress. To protect the long bones from stress, the plate's modulus of elasticity will have to exceed in comparison with the bone to which it is attached. Osteoporosis and reduction in bone strength are the result of protection from stress or shielding in long bones [15].

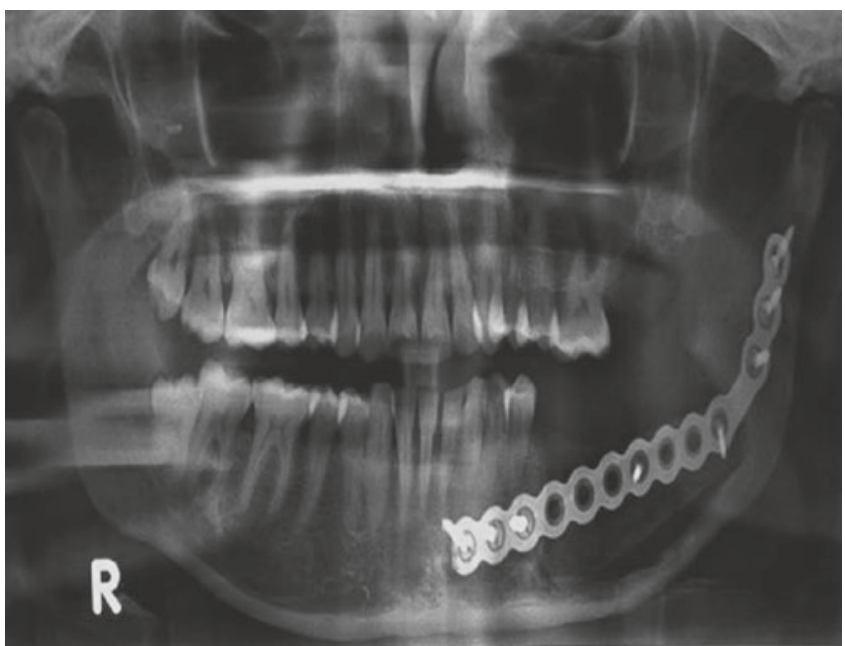

(C)Association of Oral and Maxillofacial Surgeons of India

Fig.51.6 Angle reconstruction plate

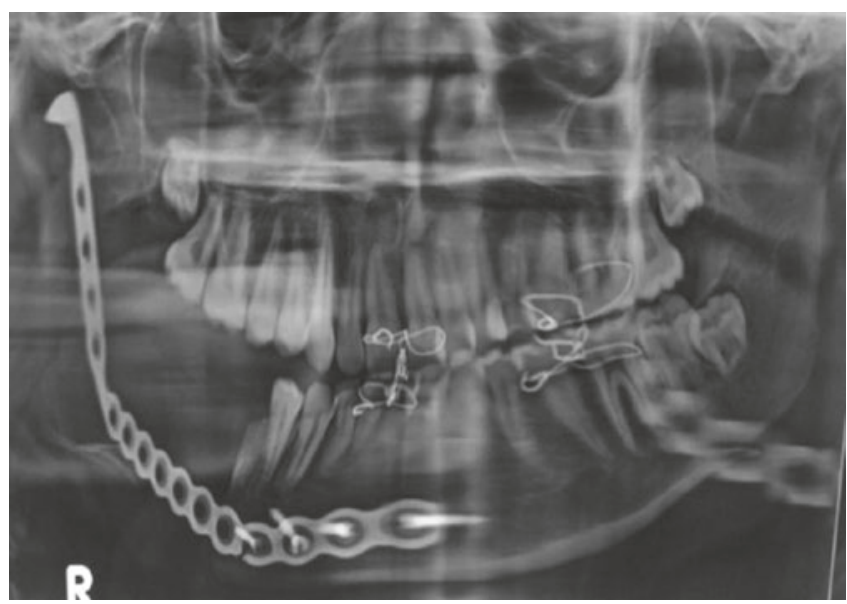

CAssociation of Oral and Maxillofacial Surgeons of India

Fig. 51.7 Condylar reconstruction plate

\subsubsection{Lag Screw Fixation}

In oral and maxillofacial surgery, Brons and Boeriing introduced lag screw fixation for the first time in 1970. According to them two lag screws prevent rotational movements of the fracture fragments in oblique mandibular fractures [16].

\subsubsection{The Principle of Lag Screw}

The lag screw principle is used whenever two wide contact surfaces of the bone should be pressed together (for mandibular oblique sagittal fractures or onlay graft fixation). 


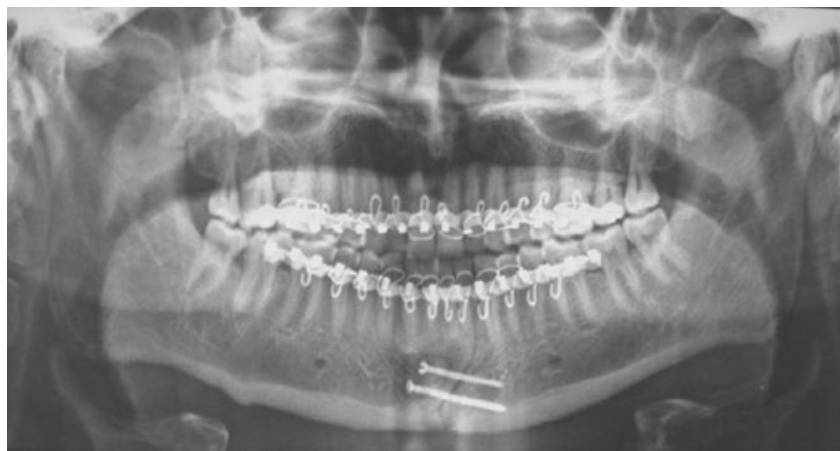

CAssociation of Oral and Maxillofacial Surgeons of India

Fig. 51.8 Orthopantomogram showing fixation with lag screws

Through the outer cortex or onlay graft, the drilling of the hole was carried out of the identical diameter to that of screw so that the screw slips through the outer cortex. The lag screw drill, which is of the same diameter as the screw, will simultaneously create a conical countersink to provide an optimal fitting of the screw head. The inner cortex is then perforated with the normal surgical drill, and the screw is inserted. It grips the inner cortex and, when tightened, exerts great force to pull the outer segment into close contact with the inner one. This principle can be used in oblique sagittal mandibular fractures, with the placement of at least three screws, or in combination with the plate, lagging only one or two of the total minimum number of screws (Fig. 51.8).

\subsubsection{Absolute Rigid Fixation Provided by Lag Screw}

Lag screw should be selected in patients having sufficient bone available for placement of two screws; dissolution of the bone around the screws results in cases of micromotion. The lag screw should be placed in the direction perpendicular to the line of fracture to avoid displacement or overriding during tightening of the screws.

Advantages of lag screws over bone plates:

1. Lag screws require less hardware hence cost-effective.

2. Absolute rigid fixation.

3. Quick and easy to use.

4. Accurate reduction.

\section{Disadvantages}

As the lag screw fixation relies on compression of bone fragments and if intervening bone is unstable due to comminution or missing, there will be segment overriding or fracture gap shortening, resulting in malocclusion.

\subsubsection{Comparison of Lag Screw Fixation Methods with Different Methods of Fixations [17-19]}

1. Single lag screw with arch bar, without MMF is sufficient enough in the treatment of anterior mandible indirectly reducing the cost and requiring less hardware and time of healing [17].

2. Lag screw fixation and plating showed excellent outcome in anterior mandible fracture; lag screws technique is difficult but associated with less postoperative complications [18].

3. In mandibular angle fracture, the lag screw demonstrates smaller inter-fragmentary gap in comparison with miniplate fixation [19].

4. Lag screw osteosynthesis is more advantageous for ramus height restoration in comparison with miniplates and Kirschner wires, in patients with condylar process fractures [20].

\subsubsection{Champy's System [21]}

Different treatment principles using monocortical miniplates without axial compression for treatment of mandibular and midface fractures were introduced, namely, by Michelet et al. in the late 1960s, which they published in 1973.

Michelet's work has been elaborated by Champy et al. for the management of mandibular angle fracture by the use of intraoral monocortical miniplates. The ideal line of osteosynthesis has been followed by Champy for plates fixation (Fig. 51.9).

It is based on the principle of neutralizing unfavorable traction strains while at the same time allowing transmission of favorable compression forces. The biomechanical validity of Michelet principles was confirmed in a series of multidisciplinary experiments performed in Strasbourg, France, between 1971 and 1974 [21].

\section{Advantages}

1. Smaller incision required

2. Less soft tissue dissection

3. Less palpable

4. Decrease stress shielding effect

5. Less chance of dental injury because of monocortical screws

6. Less chances of infection

With this type of fixation, there is adequate stability to allow direct bony union and is called as functionally stable fixation. There are many fixation techniques used in oral and maxillofacial surgery (OMFS) which are not rigid fixation truly but classified as functionally stable fixation. 


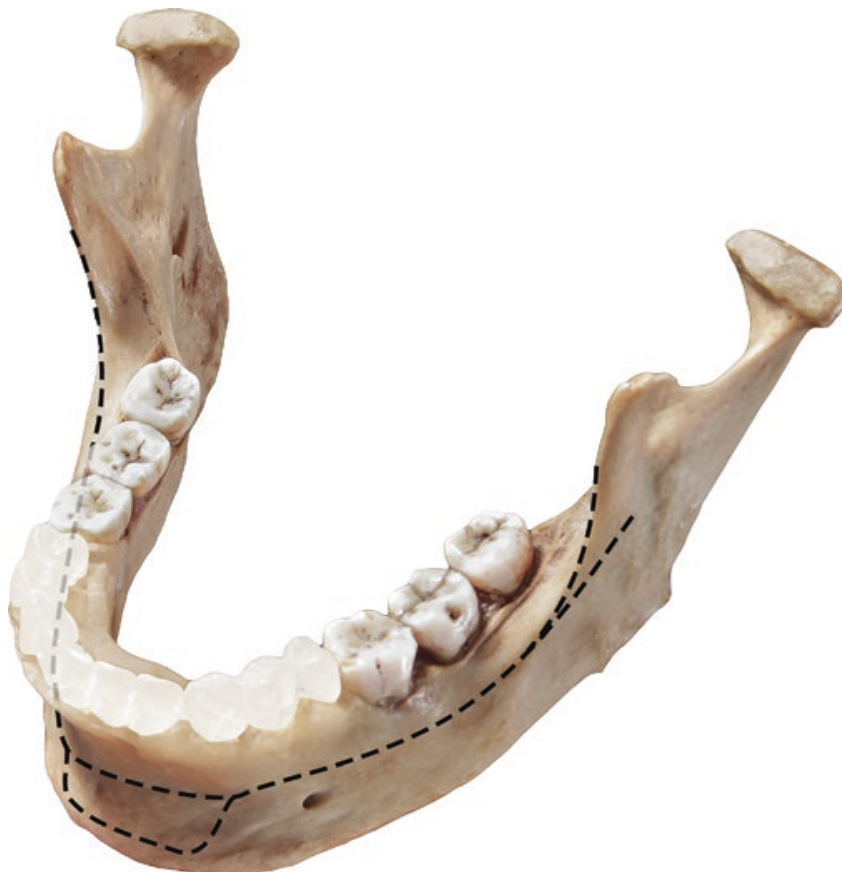

CAssociation of Oral and Maxillofacial Surgeons of India

Fig. 51.9 Champy's ideal line of osteosynthesis

\subsubsection{Materials}

Plates and screws are made up of pure titanium. The miniplates are $2 \mathrm{~cm}$ long, $0.9 \mathrm{~mm}$ thick, and $6 \mathrm{~mm}$ wide. They had an elastic limit of flexibility between 70 and 80 per square millimeter, and their rupture point lies between 95 and 110 decanewton (daN) per square millimeter (Fig. 51.10).

\subsubsection{Miniplates (Fig. 51.11)}

- The miniplates vary in length from 2 to $9 \mathrm{~cm}$ with a thickness of $0.9 \mathrm{~mm}$. They come in different lengths such as 2 holes with gap, 3 holes, 4 holes, 6 holes, and 8 holes to 16 holes with gap or continuous plates.

- The four-hole and six-hole plates are available with intermediate spacing.

- A wide variety of pre-shaped plates like L, X, Y, T, and K, delta shaped, and 3D- and $\mathrm{H}$-shaped plates are also available. $2.1 \mathrm{~mm}$ is the minimum diameter of the hole in the plate and has a bevel of $30^{\circ}$.

\subsubsection{Screw}

- All screws are cortical and self-tapping and have cruciform head.

- Available in lengths of 5, 6, 7, 9, 11, 13, and $15 \mathrm{~mm}$.

- $2 \mathrm{~mm}$ is the diameter of the screw with 1.6 core diameter of thread.

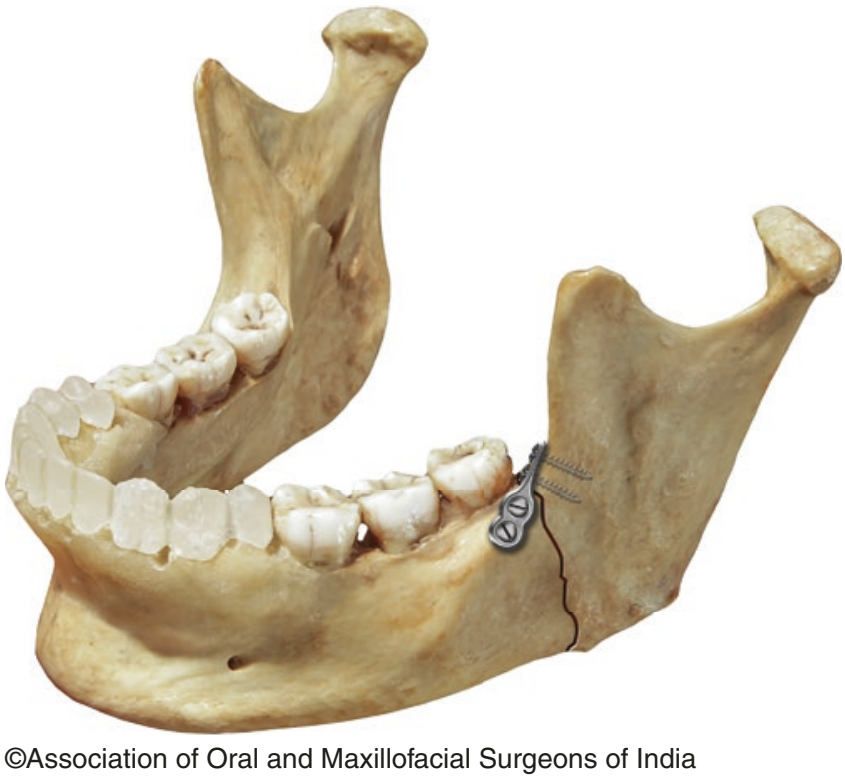

Fig. 51.10 Champy's miniplate

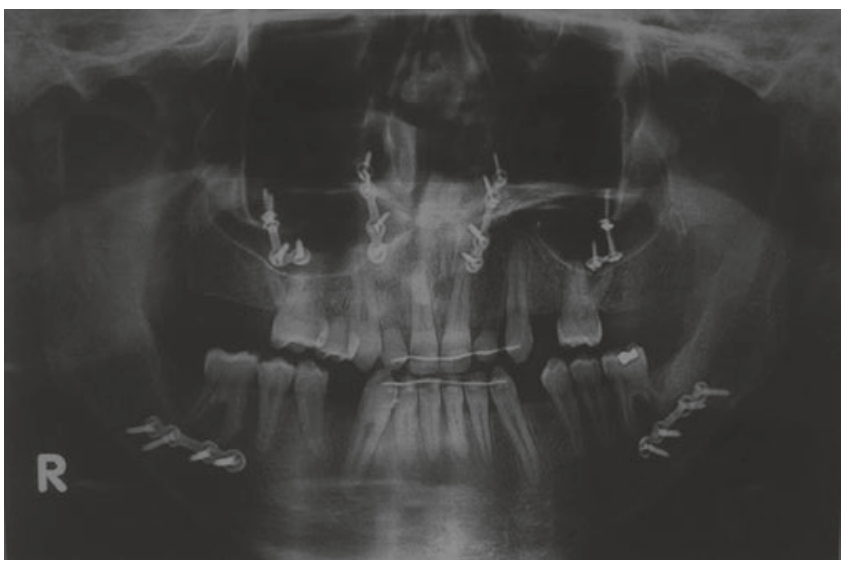

CAssociation of Oral and Maxillofacial Surgeons of India

Fig. 51.11 OPG showing fixation with the help of miniplates after Leefort I and bilateral sagittal split osteotomy

- The screw thread is $10 / 10$, so that one turn of the screw corresponds to $1 \mathrm{~mm}$ penetration into the bone.

- $2.8 \mathrm{~mm}$ is the screw head diameter, and it is designed such that it allows insertion at 30-degree angle with respect to the plate surface.

The drill has the same diameter as the core of the screws-1.6 mm. This ensures firm anchorage of the selftapping screws.

\subsubsection{Biomechanical Properties of Screw}

(Fig. 51.12) [22]

- The external or the outer diameter ranges from 0.8 to $2.0 \mathrm{~mm}$. Core diameter of the screw is its internal diameter. The surgical bone screws act by clamping the bone plate and bone together. 


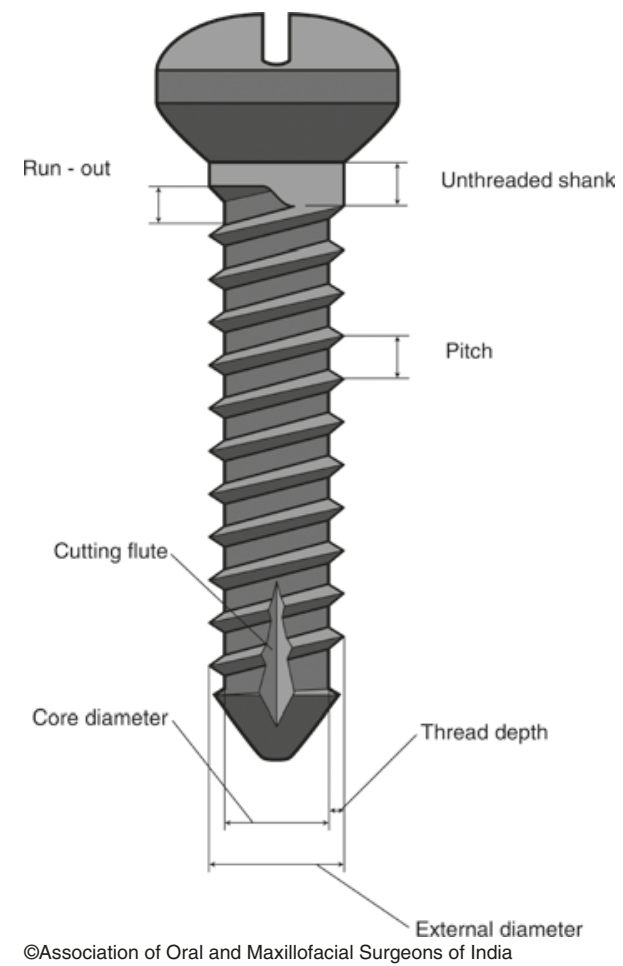

Fig. 51.12 Biomechanical properties of screw

- The pitch of the screw is calculated parallel to the screw axis from a point on one thread to corresponding point on the adjacent thread.

- The difference between core and external diameter is the thread depth.

- The distance between screw runout and screw head is the length of the unthreaded shank.

- The distance between screw runout and plate is the length of the unthreaded shank with plate.

\subsubsection{Self-Tapping and Drilling Screws}

Self-tapping screw: The screw which is inserted into a predrilled hole without tapping a screw head is the self-tapping screw.

Self-drilling screw has a drilled-shaped point to cut and does not require predrilling. Self-drilling screws have several advantages over the self-tapping such as it does not require drilling the hole and prevents thermal damage leading to infection, screw loosening, osteomyelitis, and nonunion. It also prevents damage to tooth roots and nerves by the use of drills and also avoids the complications associated with drill bit fracture.

\subsubsection{Monocortical vs. Bicortical Screws}

The monocortical screws are generally used for fixation of mandibular fractures and after sagittal split osteotomy. Chug H-IJ et al. [ 26] also concluded that monocortical screws provide stable fixation. Also chances of damage to the vital structure like inferior alveolar and lingual nerve are less with monocortical screws. Bicortical screws are usually used at the lower border of the mandible for fixation.

\subsubsection{Microplates}

The microplate fixation concept was introduced by Luhr in 1988. They are composed of cobalt, vitallium alloy, and molybdenum in the percentage of $68 \%, 27 \%$, and $5 \%$, respectively. It has got excellent physical strength and corrosion resistance.

The thickness of plate is $0.5 \mathrm{~mm}$, and the diameter of the screws is $0.8 \mathrm{~mm}$. In all the three dimensions, they can be contoured and maintained an excellent degree of rigidity for osseous segment stabilization. They are used in:

1. Nasoethmoidal fractures

2. Fractures of infraorbital area

3. Fracture of frontal sinus wall

4. Reconstruction of the skull

5. Infant craniofacial surgery

\subsubsection{Micromesh}

Inspite of its reduced thickness $(0.3 \mathrm{~mm})$, micromesh is remarkably strong. It is available in sizes of 40 by 60 and 60 by $100 \mathrm{~mm}$. Template made of a soft, malleable tin alloy comes in various sizes. The template is cut to the shape and size required in the individual case, and then it is contoured to the bone surface. The actual titanium micromesh is then cut out with a wire cutter and contoured on the instrument table reduplicating the individual shape of the template.

\subsubsection{AO/ASIF System [27]}

The association of osteosynthesis/association for the study of internal fixation (AO/ASIF) were founded by a group of 15 Swiss surgeons in 1958. The group was led by Maurice E. Muller; AO/ASIF investigators have documented the biologic basis for the concepts on which rigid fixation techniques are based.

Spiessl applied AO/ASIF concepts of long bone healing and modified AO/ASIF instrumentations for use in mandible in the late 1960s and early 1970s. 
Compression can be achieved through static or dynamic means. The two devices that produce static compression are the self-compression plate and lag screw.

1. The self-compression plate designed by Perren for the ASIF has been called the dynamic compression plate (DCP). It generates interfragmentary compression by spherical guiding principle. The DCP principle causes the movement of screw in both vertical and horizontal direction which compresses the fracture segments.

2. Lag screw principle-when the screw is tightened, it compresses the surface when the screw glides through the cortex of one fragment and engages the cortex of the opposite fragment.

The EDCP (eccentric dynamic compression plate) has outer hole which is oblique causing compression on alveolar side and longitudinal inner holes creating basal side interfragmental compression. EDCPs eccentric action eliminates the need for tension band. This plate has most utility for simple fracture of the posterior region where there are no teeth available for splinting.

The reconstruction plate is a load-bearing plate and absorbs the entire functional load. They are designed for use without the tension band. It is large and reinforced version of basal stabilization plate. They can be adapted to local bony contours and are malleable. Depending on the placement of drill hole, it has two-way DC holes that enable compression to be applied in either longitudinal direction.

\subsubsection{Plates}

(I) Linear system (compression plates)

(a) DCP plates

(b) EDCP plates

(II) Universal systems (reconstruction plates)

\subsubsection{Dynamic Compression Plate (DCP)}

These are designed to withstand tensile loading force in the mandible. In mandibular angle, body, and symphysis regions, they can be used comfortably. It can be applied intraorally or through an extraoral incision. It is used with a tension band. The dynamic compression plate was developed in 1969.

The DCP has a self-compressing hole design. The holes are oblong, and the portion of each hole distant from the fracture has a sloping form or "shoulder."

Experimental work showed that the flat undersurface of the DCP interfered with the vascular supply of the underlying cortex onto which it was compressed by the screws. The concept of "footprint" is the area of undersurface of the plate in contact with the underlying bone cortex.
Principles of $\mathrm{DCP}$ - The sloping shoulder of the DCP hole has the form of part of an angled cylinder. If a screw is inserted eccentrically, so that its head on final tightening slides down the sloping profile of the hole, the screw/bone unit will be shifted toward the fracture, and the fracture plane will thereby be compressed. Such a screw is often referred to as a load screw.

\subsubsection{Eccentric Dynamic Compression Plate (EDCP) [27]}

It produces a compressive force via arrangement of eccentric and centric (axial) plate holes. EDCP are $8 \mathrm{~mm}$ wide and come in four-hole (36 mm long) and six-hole (42 mm long) lengths. The stainless steel plates are $2 \mathrm{~mm}$ thick, and the titanium plate is $2.2 \mathrm{~mm}$ thick. At the fractures alveolar side, the compression has been provided by the $75^{\circ}$ angulation. It is important to place the sloped edge of the angled hole at the mandibular lower border (if the plate is placed upside down, it will tend to distract bone edges at the alveolar border). First central screws are inserted in EDCPs (longitudinal hole eccentrically away from the fracture) than at the lower border; screws are placed in the 75-degree oblique holes eccentrically and in the last rest of the screws inserted in a neutral position. When the plates and tension band splint cannot be used, in those situations EDCP plates are used. The reduction forceps with pressure splinting are useful initially to reduce and compress the fragments when applying the EDCP plate.

\subsubsection{Bioresorbable Fixation Systems}

Use of titanium plates and screws is time-tested for their use in management of craniofacial fractures. However, it has many drawbacks including infection, hardware palpation and visibility, hypersensitivity to temperature changes, and stress shielding effect. They also interfere with radiographic examination. Sometimes, metal ions leach out into soft tissues. In view of these complications, bioresorbable implants were developed hoping to reduce hardware-associated complications as well as the necessity for hardware removal.

The use of bioresorbable fixation devices must be limited as their mechanical strength is inferior as compared to the titanium hardware. They can be effectively used in low loadbearing areas of maxillofacial skeleton like maxilla, zygoma, and upper regions of face. The bioresorbable system may not be strong enough to provide adequate stability in mandible fractures which are comminuted, as it is a load-bearing bone. It can be used in simple mandibular fractures.

Bioresorbable fixation systems stabilize fracture segments long enough for fracture healing and union to occur then dissolve, thereby reducing complications frequently 
encountered with metallic hardware such as palpability, visibility, cold sensitivity, and need for removal. Most commonly polylactic acid (PLA) is used in bioresorbable plates.

\section{Complications [28]}

1. For allowing the polymer chains to bend without breaking, a heat source is required. Also, the working time is limited to $8-10 \mathrm{~s}$.

2. Screw insertion requires pretapping the screw.

3. Increased operative time.

4. More expensive.

5. PLA decreases stress shielding compared to LD-DC plates.

\subsection{Recent Developments}

To reduce the stress shielding, reduction in modulus is the answer to correct the disadvantages of internal fixation. To improve the healing of the fracture under the plates, the only solution is to allow micromotion through the fracture site; the design should be made in such a way that it resists torsional, bending, and shear movements.

\subsubsection{Three-Dimensional (3D) Plates} (Fig. 51.13)

The two miniplates are connected by interconnecting crossbars which are used as 3D plates. Technically, they are not three-dimensional structures, but their closed quadrilateral shape provides stability in all three dimensions.

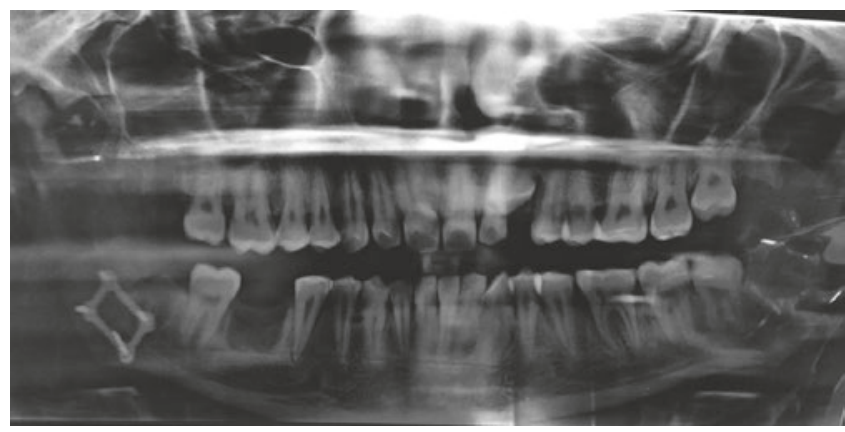

CAssociation of Oral and Maxillofacial Surgeons of India

Fig. 51.13 Orthopantomogram showing fixation with threedimensional plate

\subsubsection{Virtual Surgical Planning, Computer- Assisted Design, and 3D Modelling}

The management of the facial fracture is very challenging due to its unique three-dimensional contours and nonlinearity of facial skeleton. The recent development in the software technology and 3D modeling has revolutionized the treatment. They can be used as an adjunct to the standard preoperative preparation.

To reduce the operating time in the operation theater, the $3 \mathrm{D}$ models can serve as a template on which pre contouring of the fixation plates can be done. Custom-designed titanium implants can be made with the help of 3D printers to get the accurate fit. They can be preferred over the conventional implants and reduce the surgical time. The model design and virtual surgical planning help in constructing the guides which can be used perioperatively, can design the optimal approach preoperatively, and can compare the actual outcome to the virtual design. To reconstruct the multitude of craniomaxillofacial defects of mandible, zygoma, midface, and orbit, these technologies are very helpful. 3D modeling and computer-assisted surgical planning have been very helpful in managing the complications associated with these injuries.

\subsubsection{Intraoperative Imaging [29]}

Intraoperative imaging is very important in assessing the reduction and fixation of all maxillofacial fractures, and according to its feedback, the surgeons can immediately make corrections of any error that occur during reduction and fixation, which indirectly reduces the complications and avoids potential resurgeries. Computed tomography (CT) is commonly used for the same purpose.

\subsection{Conclusion}

For the treatment of maxillofacial fractures, many fixation methods have been used with great success. To reestablish the pre-injury esthetics, the normal masticatory function and the proper occlusion in cases of such fractures are the main objectives of the treatment. Maxillomandibular fixation can be done for the conservative management of such fractures which can be carried out with the help of arch bars, wiring, and cap splints and in edentulous patients by gunning splints. The open reduction and internal fixation can be carried out 
with the help of miniplates, microplates, 3D plates, and reconstruction plates. Different plating systems and wiring techniques make the management of these maxillofacial fractures predictable with high success rate.

Acknowledgment Author wishes to thank Dr. Anshul Rai for providing Figs. 51.6, 51.7, 51.11, and 51.13.

\section{References}

1. Uhtoff HK, Poitras P, Backman DS. Internal plate fixation of fracture: short history and recent developments. J Orthop Sci. 2006;11:118-26.

2. Fonseca RJ, Walker RV, Barber HD, Powers M, Frost DE. Oral and maxillofacial trauma. China: Saunders; 2013.

3. Ehrenfeld M, Manson PN, Prein J, AOCMF. Principles of internal fixations of craniomaxillofacial skeleton, trauma, \& orthognathic surgery. Basel: Thieme; 2012.

4. Rowe NL, William JL. Maxillofacial injuries. 1st edn. New York: Churchill Livingstone. ISBN: 978-81-312-1840-2.

5. Rudderrnan RH, Mullen RL. Biomechanics of the facial skeleton. Clin Plast Surg. 1992;19:11.

6. Greenberg AM, Prein J. Craniomaxillofacial reconstructive and corrective bone surgery. Principles of internal fixation using the AO/ASIF technique. New York: Springer. p. 101-3.

7. Allgöwer M, Spiegel PG. Internal fixation of fractures: evolution of concepts. Clin Orthop. 1979;138:26-9.

8. Uhthoff HK, Poitras P, Backman DS. Internal plate fixation of fractures:short history and recent developments. J Orthop Sci. 2006;11:118-26.

9. Egol KA, Kubiak EN, Fulkerson E, Kummer FJ, Koval KJ. Biomechanics of locked plates and screws. J Orthop Trauma 2004;18:488-93.

10. Herford AS, Ellis E. Use of a locking reconstruction bone plate/ screw system for mandibular surgery. J Oral Maxillofac Surg. 1998;56:1261.

11. Klotch DW, Gal TJ, Gal RL. Assessment of plate use for mandibular reconstruction: Has changing technology made a difference? Otolaryngol Head Neck Surg. 1999;121:388.

12. Coletti DP, et al. Comparative analysis of the threaded and tapered locking reconstruction plates. J Oral Maxillofac Surg. 2007;65:2587-93.
13. Spiessl B. Rigid internal fixation of fractures of lower jaw. Reconstr Surg Traumatol. 1972;13:124-40.

14. Scolozzi P, Richter M. Treatment of severe mandibular fractures using AO reconstruction plates. J Oral Maxillofac Surg. 2003;61:458-61.

15. Waris P. Torsional strength of cortical and cancellous bone grafts after rigid plate fixation. Acta Orthop Scand. 1981;52:249.

16. Bansal P, Kumar S, Mishra V, Jaiswal Y, Das G. Evaluation of titanium lag screw osteosynthesis in the management of mandibular fractures. World J Dent. 2017;8(4):315-20.

17. Emam HA, Stevens MR. Can an arch bar replace a second lag screw in management of anterior mandibular fractures? J Oral Maxillofac Surg. 2012;70(2):378-83.

18. Ellis E. Is lag screw fixation superior to plate fixation to treat fracture of mandibular symphysis? 3rd J Oral Maxillofac Surg. 2012;70(4):875-82.

19. Schaaf $\mathrm{H}$, et al. Comparison of miniplate versus lag screw osteosynthesis for fractures of mandibular angle. Oral Surg Oral Med Oral Pathol Oral Radiol Endod. 2011;111(1):34-40.

20. Sugiura T, et al. A comparative evaluation of osteosynthesis with lag screws, miniplates, or Kirschner wires for mandibular condylar process fractures. J Oral Maxillofac Surg. 2001;59(10):1161-8, 1169-70.

21. Michelet FX, Deymes J, Dessus B. Osteosynthesis with miniaturized screwed plates in maxillo-facial surgery. J Maxillofac Surg. 1973;1(2):79-84.

22. You Z-H, et al. Biomechanical properties of small bone screws. $\mathbf{J}$ Oral Maxillofac Surg. 1994;52:1293-302.

23. Champy M, Lodde JP, Schmitt R, et al. Mandibular osteosynthesis by miniature screwed plates via the buccal approach. J Maxillofac Surg. 1978;6:14

24. Baumgart FW, Cordey J, Morikawa K, et al. AO/ASIF self-tapping screws (STS). Injury. 24 (suppl 1):S1.

25. Heidemann W, Gerlach KL, Gröbel KH, et al. Drill free screws: A new form of osteosynthesis screw. J Craniomaxillofac Surg. 1998;26:163.

26. Chung H-IJ, et al. Postoperative stability after sagittal split ramus osteotomies for a mandibular setback with monocortical plate fixation or bicortical screw fixation. J Oral Maxillofac Surg. 2008;66:446-52.

27. Yaramchuk MJ, Gruss JS, Manson PN. Rigid fixation of the craniomaxillofacial skeleton: Part II: Implant system for rigid fixation of craniomaxillofacial skeleton.

28. Cutright DE, Hunsuck EG. The repair of fractures of orbital floor using biodegradable polylactic acid. Oral Surg. 1972;33:28-34.

29. Meaike JD, Hollier LH. Updates in facial fracture management. J Trauma Treat. 2015;4:4

Open Access This chapter is licensed under the terms of the Creative Commons Attribution 4.0 International License (http://creativecommons. org/licenses/by/4.0/), which permits use, sharing, adaptation, distribution and reproduction in any medium or format, as long as you give appropriate credit to the original author(s) and the source, provide a link to the Creative Commons license and indicate if changes were made.

The images or other third party material in this chapter are included in the chapter's Creative Commons license, unless indicated otherwise in a credit line to the material. If material is not included in the chapter's Creative Commons license and your intended use is not permitted by statutory regulation or exceeds the permitted use, you will need to obtain permission directly from the copyright holder. 